\title{
Perceived Stress During the COVID-19 Pandemic Mediates the Association Between Self-quarantine Factors and Psychological Characteristics and Elevated Maladaptive Daydreaming
}

\author{
Barış Metin $^{1}$ (D ) Eli Somer ${ }^{2} \cdot$ Hisham M. Abu-Rayya ${ }^{2,3} \cdot$ Adriano Schimmenti $^{4}$. \\ Buse Göçmen ${ }^{1}$
}

Accepted: 27 August 2021

(C) The Author(s), under exclusive licence to Springer Science+Business Media, LLC, part of Springer Nature 2021

\begin{abstract}
Since the emergence of the COVID-19 pandemic, almost all countries have employed varying degrees of lockdown measures to limit the spread of the infection. Previous studies showed that individuals with maladaptive daydreaming (MD) are affected negatively by the lockdown. In this study, we explored a set of lockdown measures (e.g., self-quarantine) and personal factors (e.g., education, history of depression, and personality traits) that might potentially exacerbate MD experienced during the lockdown period. We also examined whether perceived stress acted as a mediator in the relationship between these factors and MD. During the first lockdown from April to June, we analyzed data provided by 1083 individuals from the USA, the UK, Italy, and Turkey. A path analysis revealed that perceived stress mediated the effects on MD of self-quarantine, previous episodes of depression, low education level, and introversion and emotional instability. Our study suggests a conceptual framework for the factors that intensify maladaptive daydreaming under the threats of the pandemic and forced home confinement, offering implications for interventions with vulnerable populations.
\end{abstract}

Keywords COVID-19 · Psychological stress · Maladaptive daydreaming · Path analysis

Barış Metin and Eli Somer contributed equally to this work.

Barış Metin

baris.metin@uskudar.edu.tr

1 Psychology Department, Üsküdar University, Altunizade Haluk Türksoy Sk. No:14, 34662 Üsküdar-İstanbul, Turkey

2 School of Social Work, University of Haifa, Haifa, Israel

3 School of Psychology and Public Health, La Trobe University, Melbourne, Australia

4 Faculty of Human and Social Sciences, Kore University of Enna, Enna, Italy 


\section{Psychological Effects of the COVID-19 Pandemic}

The emergence of a new strain of a zoonotic agent in Wuhan province of China in December 2019 (the 2019 novel coronavirus, COVID-19) was declared a worldwide pandemic by the World Health Organization. Throughout 2020, the COVID-19 has continued to inflict global chaos, as the numbers of confirmed cases and related mortalities continued to rise. The disease manifests itself with fever, cough, malaise, and pneumonia symptoms that emerge after an incubation period. The 2-14-day incubation time of the Coronavirus is an important factor in contagion because new carriers of the virus may unknowingly spread the disease before symptoms can develop (Centers for Disease Control and Prevention, 2021). In an effort to reduce close contact among citizens, governments ordered the closure of public places causing the shutdown of the shopping and retail, hospitality, entertainment, recreation and sport, transportation, and educational systems. As disease rates soared, authorities implemented lockdowns to various degrees, with some governments enforcing total curfews. This enduring global health emergency, along with worldwide efforts to curb the spread of the virus, has not only presented exceptional challenges for the working lives and careers of millions of individuals (Sohrabi et al., 2020; Wang et al., 2020) but also led to unparalleled worldwide effects on human well-being.

Fear of falling sick or dying, feeling worried and helpless, and experiencing stigma have been among the emotional effects experienced during the COVID-19 pandemic (Schimmenti, Billieux, \& Starcevic, 2020a). The emotional effects on individuals were further aggravated with the closure of schools and businesses, adding worries about endangered family members and economic survival (Van Bortel, 2016). Previous studies on the psychological effects of the SARS outbreak on non-infected people have revealed significant psychiatric problems associated with younger age and increased self-blame (Sim, 2010). This finding has gained further support in the current pandemic. For instance, Kowal et al. (2020) and Brooks et al. (2020) reported that young age and the severity of pandemic stressors were related to increased levels of perceived stress and serious psychological crises. Self-isolation and quarantine were specifically associated with elevated levels of anxiety, anger, and confusion (Brooks et al., 2020), depression, mood swings, irritability, insomnia, inattention, anger, and post-traumatic symptoms (Rubin \& Wessely, 2020). A good illustration of the psychological impact of the pandemic was presented in a recent analysis based on self-report data collected from a large sample of Canadians during early pandemic. This study shows that, while at the time of this survey, the impact of pandemic was low (number of cases between 1000 and 2000, see https://www.worldometers.info), high-level anxiety was 4 times higher and high-level depression was 2 times higher as compared to pre-pandemic times (Mental Health Research Canada, 2020).

International public health emergencies require the development of strategies to mitigate the negative psychological effects on individuals (Wang et al., 2020). It is important to identify psych-social risk factors that may exacerbate psychopathology during such sustained public emergencies so that adjusted interventions can be implemented. Thus far, research has recognized a set of such factors. For example, among those who may be more severely affected by the pandemic are individuals with (1) low educational level (Megatsari et al., 2020, Li, 2020), (2) compromised social skills causing a further decrease in their social competence, (3) emotional regulation problems causing amplified anxiety responses (Preti et al., 2020), (4) a history of a psychiatric condition 
(Wathelet et al., 2020), (5) previous exposure to depressive episodes (Holingue et al., 2020), and finally, (6) introversion and emotional instability personality traits, which elevate individuals' vulnerability to threat during the pandemic (Preti et al., 2020; Liu et al., 2020).

Accumulating evidence suggests that a major mental health outcome of the current pandemic is the worsening of addictive "self-medication" practices (Khantzian, 1997) such as the consumption of alcohol (Chodkiewicz et al., 2020), substance abuse (Rogers et al., 2020) and escapist behaviors such as online gambling (Price, 2020), excessive smartphone usage (Elhai et al., 2020), and online gaming (Balhara et al., 2020). The current study wishes to focus on the impact of stress associated with the current pandemic on a newly emerging clinical condition that can also be conceptualized in terms of an addictive mental behavior often functioning as self-medication, that is, maladaptive daydreaming (MD, Somer, 2002).

\section{Maladaptive Daydreaming During the Pandemic}

Daydreaming and mind-wandering are prevalent normal mental activities that occupy almost half of all human thought, in hundreds of short daily fantasy episodes involving self-created thinking that diverge from the current activity (Klinger, 2009). This mental activity is likely to have evolutionary utilities as it may help survival via better future planning (Mooneyham \& Schooler, 2013). In contrast, MD characterizes individuals who are absorbed daily in vivid daydreaming in a manner that causes clinically meaningful distress or diminishes performance in social, occupational, or other important areas of life (Somer, 2002). MD is associated with a strong yearning, it can be activated or maintained by evocative music, and is often accompanied by stereotypical physical movements such as pacing, swinging, or hand movements (Somer, 2002). Although maladaptive at a functional level, immersive daydreaming (West \& Somer, 2020), the trait underlying MD, may confer individuals with stress tolerance (Pietkiewicz et al., 2018). In other words, it might be a form of autistic fantasy a person employs to avoid stress related to real-life problems (Schimmenti et al., 2019).

Previous studies on MD during the COVID-19 pandemic showed that individuals with MD experience an elevated daydreaming frequency and intensity (Somer et al., 2020), as well as heightened depression, anxiety, and reduced online social relationships (Musetti et al., 2021). In the current study, we aimed to explore under objective stress conditions and in real time the roles of lockdown factors, specific personal characteristics, and perceived stress in MD.

Extraversion is a personality trait characterized by friendliness, assertiveness, and high energy levels (Soto \& John, 2017). The literature suggested that extraversion could moderate the relationship between the severity of imposed measures and psychopathology (Brooks \& Moser, 2020; Steel et al., 2008). They argued that the change in lifestyle associated with the lockdown measures would feel more natural to introverts, who tend to avoid social engagement (Woodcock et al., 2013) and who could unashamedly prefer solitude over engagement with others. Support for this idea was provided by Wijngaards et al. (2020) who showed that although severe social distancing measures generally help extraverts who tend to feel safer and worry less, the ensuing restricted lifestyle felt more natural to introverts. However, since individuals with MD prefer privacy to engage in their abnormal mental activity, we suspected that introversion would be associated with elevated MD. 
Because individuals with low levels of emotional stability are more likely to experience stress during lockdown (Liu et al., 2020), we also suspected that emotional instability will be related to stress perception. Besides, we expected that people with a propensity for depression would face greater stress levels during the lockdown as compared to individuals with lower levels of depression (Holingue et al., 2020). Based on previous studies, we also envisaged that the education level would inversely affect an individual's perceived stress level (Li, 2020; Megatsari et al., 2020). Thus, perceived stress acts as the principal mediator in our conceptual model (see Figure 1). Research suggests that education would covary with the employment of self-quarantine since individuals with a higher level of education are likely to follow quarantine rules more strictly. Furthermore, it is also known that individuals with higher education have higher emotional stability and extraversion (OECD Education at a glance report, 2012; Andersen et al., 2020). Therefore, the covariance between self-quarantine and education and that between education and personality traits are taken into account in our attempt to understand the relationships between lockdown factors, personal characteristics, perceived stress, and MD, as shown in Fig. 1.

\section{Perceived Stress}

Stress-related and psychiatric disorders are, according to the World Health Organization (WHO), the second most common non-communicable health concern worldwide (Murray et al., 2012). The literature suggests that perceived stress correlated strongly with reported health complaints (Wiklund et al., 2012), more mental health symptoms, in general (Thorsen et al., 2016), and with elevated anxiety and depression, in particular (Bergdahl $\&$ Bergdahl, 2002). In the context of the current pandemic, perceived stress was associated with anxiety and depression in hospitalized patients with COVID-19 (Zandifar et al., 2020) and socially isolated people (Xu et al., 2020), demonstrating the potential role of subjective threat appraisal during this unprecedented crisis.

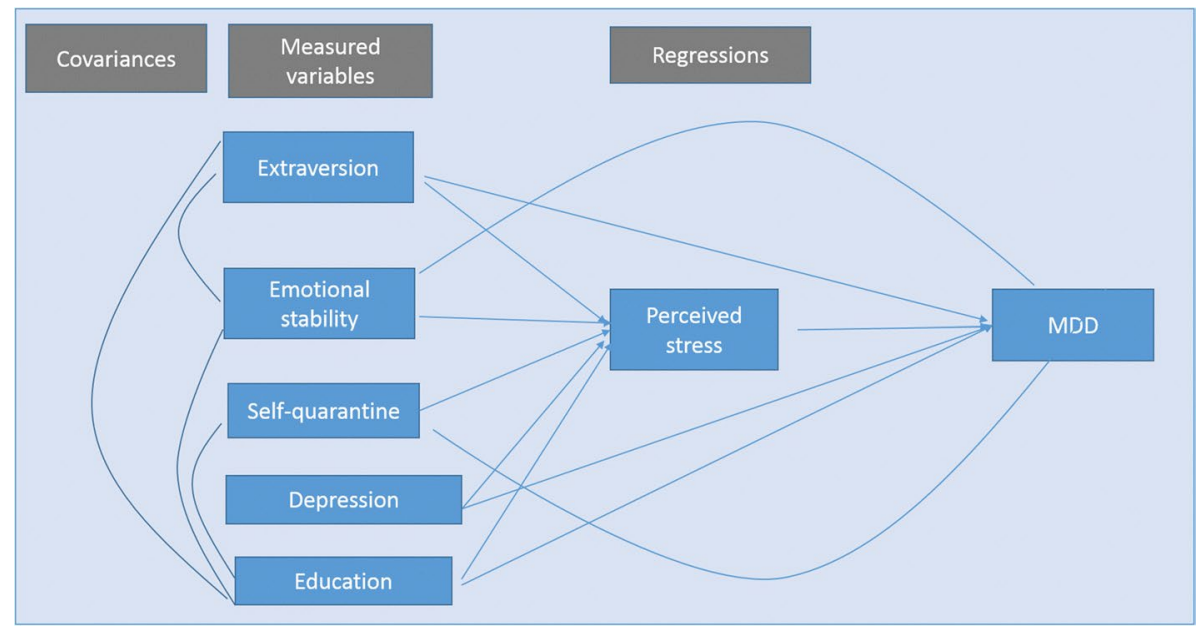

Fig. 1 Conceptual model of relatioships between lockdown factors, personal characteristics, perceived stress, and MD 


\section{The Present Study}

The current pandemic is a major cause of uncertainty, fear, and stigmatization requiring the execution of adequate mental health interventions tailored to the specific needs of susceptible populations (Schimmenti, Billieux, \& Starcevic, 2020a) who may perceive risks differently. With this in mind, our suggested conceptual model (Figure 1) may refine our understanding of how clinical history and personal characteristics can explain the symptoms of maladaptive daydreaming during a stressful pandemic. Our first hypothesis is that self-quarantine, previous episodes of depression, lower education level, introversion, and emotional instability will be associated with elevated MD. Our second prediction is that perceived stress during the pandemic will mediate the possible impact of these risk factors on MD.

\section{Method}

\section{Participants and Procedure}

This study was approved by the University Human Research Ethics Committees of the first and second authors' universities. Data were collected online via Qualtrics during April and May 2020 as a part of a multicenter international study. Participants completed the survey at the height of the first pandemic wave, while most countries implemented strict lockdown restrictions. The sample comprised 1796 participants from various countries. After eliminating individuals with missing data, we focused our analyses on participants from countries with samples exceeding 100 respondents: the USA $(n=356)$, Italy $(n=365)$, Turkey $(n=268)$, and the UK $(n=103)$. Participants' educational level corresponded to an elementary/high school certificate, bachelor's degree, or graduate/post-graduate degree. Moreover, the participants reported their gender, age, whether they were required to selfquarantine/isolation (yes/no), and whether they had a diagnosed pre-existing depression assigned to them by a mental health professional (yes/no). In addition to providing information on these factors, the participants completed a set of cross-culturally validated measures on maladaptive daydreaming, perceived stress, and personality administered to them in their native language. Descriptive statistics of the study variables are displayed in Table 1.

Table 1 Descriptive statistics of study variables

\begin{tabular}{lllll}
\hline & Italy & Turkey & UK & USA \\
\hline MD mean (SD) & $45.04(26.31)$ & $39.03(26.58)$ & $62.71(20.88)$ & $56.60(23.52)$ \\
Perceived stress mean (SD) & $2.24(0.76)$ & $2.24(0.71)$ & $2.51(0.71)$ & $2.49(0.72)$ \\
Extraversion mean (SD) & $3.86(1.55)$ & $4.46(1.75)$ & $2.79(1.45)$ & $2.96(1.77)$ \\
Emotional stability mean (SD) & $3.52(1.71)$ & $9.1(1.42)$ & $3.18(1.41)$ & $3.34(1.56)$ \\
Sex (\% male) & 29 & 19 & 12 & 13 \\
\% Major depression history & 8 & 8 & 21 & 33 \\
\% Self-quarantine & 32 & 41 & 52 & 46 \\
\% Education level (elementary/ & $38 / 24 / 37$ & $13 / 33 / 55$ & $40 / 32 / 28$ & $29 / 47 / 24$ \\
bachelor/graduate) & & & & \\
\hline
\end{tabular}




\section{Measures}

The recruitment of research participants during an emergency and the prevention of their dropout have been recognized as serious challenges (Knack et al., 2006). The need to retain research respondents has generated a demand for efficient measures of psychological constructs in psychology. While shorter instruments might be more limited than longer ones, they have obvious benefits in reducing the burden. Furthermore, short versions of psychological measures often show similar reliability, factorial validity, and convergent/discriminant validity to longer versions (Kemper et al., 2019). There is also evidence that a measure containing even a single, global question is sometimes likely to suffice (Bowlling, 2005). To guarantee optimal participant adherence during the current emergency, we resorted to the shortest measures available for the assessment of the target variables.

Maladaptive Daydreaming We employed Somer (2018) 16-item Maladaptive Daydreaming Scale (MDS-16) to gauge the respondents' maladaptive daydreaming. A sample item is "Some people feel distressed or concerned about the amount of time they spend daydreaming. How distressed do you currently feel about the amount of time you spend daydreaming?". Respondents selected their responses on an 11-point Likert scale ranging from 0 to $100 \%$, to indicate their daydreaming level. The scale does not contain reverse items and the total score is calculated as the mean score of 16 items. A high score on this scale shows a heightened MD level. The MDS-16 demonstrated excellent reliability in the present study (Cronbach's $\alpha=.95$ ). Previous studies also demonstrated that the scale is reliable among Turkish, Italian, and English-speaking individuals $(\alpha=.88, .95, .95$, respectively; Metin et al., unpublished data, Somer et al., 2016; Schimmenti et al., 2020b).

Personality Traits We used the 10-item Big-5 personality questionnaire (Gosling et al., 2003). This is a 7-point Likert scale (from 1-disagree strongly to 7-agree strongly) that measures emotional stability, extraversion, agreeableness, conscientiousness, and openness to experience. For each dimension, there is a regular and a reverse item. The score for each dimension is the mean of those two item scores. A higher score indicates the presence of a particular trait to a greater extent. For this study, we used the four items measuring emotional stability and extraversion. Respondents were asked to rate the extent to which a pair of traits like "extraverted/enthusiastic" (defining extraversion) or "calm/emotionally stable" (defining emotional stability) applies to them. As justified by Gosling et al. (2003), previous studies show that the personality dimensions measured by this scale correlate sufficiently to longer versions of the Big-5 scales. In the present study, Cronbach's $\alpha=.62$ for the emotional stability and .71 for extraversion traits.

Perceived Stress We used Cohen et al. (1983) 10-item perceived stress scale to quantify stress level. An example item of this 5-point Likert scale (from 0-never to 4-very often) is "In the last month, how often have you felt that you were unable to control the important things in your life?". The total score is calculated as the mean of individual items. Four items on this scale are reversed. A high score indicates increased stress perception. Cronbach's $\alpha$ reliability of the scale was .87 in the current study. 


\section{Data Analysis}

All analyses were performed using SPSS v.24 and the Lavaan package in the R statistical software. To examine if the hypothesized model in Figure 1 showed an adequate fit, we used both absolute (e.g., RMSEA, SRMR) and incremental (e.g., CFI) fit indices. Generally accepted cutoff criteria for a good fit in these indices are as follows: RMSA $\leq 0.06$, SRMR $\leq 0.08$, and CFI and TLI $\geq 0.95$ (Hu \& Bentler, 1999).

\section{Results}

\section{Preliminary Analyses}

The national samples differed significantly in MD levels, $F(3,1079)=38.44, p<.001$. As shown in Table 1, British participants had greater MD scores than respondents from other countries, and Turkish participants had the lowest MD scores. Participants from the UK and the USA reported greater perceived stress compared to their Turkish counterparts. However, since we measured relationships between variables rather than comparing samples, this national differentiation was inconsequential. As shown in Table 2, individuals were more likely to suffer from MD during the lockdown if they reported a past diagnosis of major depression. Furthermore, the less educated, more introverted, emotionally unstable the individuals were, the more severe their MD.

\section{Mediation Analyses}

The analyses evaluated the model in the combined international sample. Model fit statistics suggested a good fit. The results of Comparative Fit Index (CFI), Tucker-Lewis Index (TLI), root mean square error of approximation (RMSA), and standardized root mean square residual (SRMR) indices were within the acceptable limits of good model fit to the data $\left(\chi^{2}{ }_{(3)}=7.5, p=.06 ; \mathrm{CFI}=.996\right.$; $\mathrm{TLI}=.971$; $\mathrm{RMSEA}=.039$ [90\% C.I. $=$ $0-0.08]$, SRMR = .021). The regression estimates (see Figure 2) showed that a past diagnosis of major depression, the employment of self-quarantine, a lower level of education, introversion, and emotional instability were associated significantly with the respondents' perceived stress. Similarly, a past diagnosis of major depression, the employment of selfquarantine, a lower level of education, introversion and emotional instability, and perceived stress were all associated significantly with MD. Our indirect effect analyses indicated that

Table 2 Pearson's $r$ correlations between study variables

\begin{tabular}{llllll}
\hline & Extroversion & Emotional stability & Perceived stress & Education $^{\mathrm{a}}$ & Depression $^{\mathrm{b}}$ \\
\hline MD & $-.43^{*}$ & $-.40^{*}$ & $.51^{*}$ & $-.33^{*}$ & $.23^{*}$ \\
Extroversion & & .20 & $-.29^{*}$ & .23 & $-.16^{*}$ \\
Emotional stability & & & $-.50^{*}$ & $.14^{*}$ & $-.16^{*}$ \\
\hline
\end{tabular}

$* P<.001$

${ }^{\mathrm{a}}$ Education $=1$ (elementary/high school), 2 = bachelor degree, $3=$ graduate degree

${ }^{\mathrm{b}}$ Depression $=0$ (yes), 1 (no) 


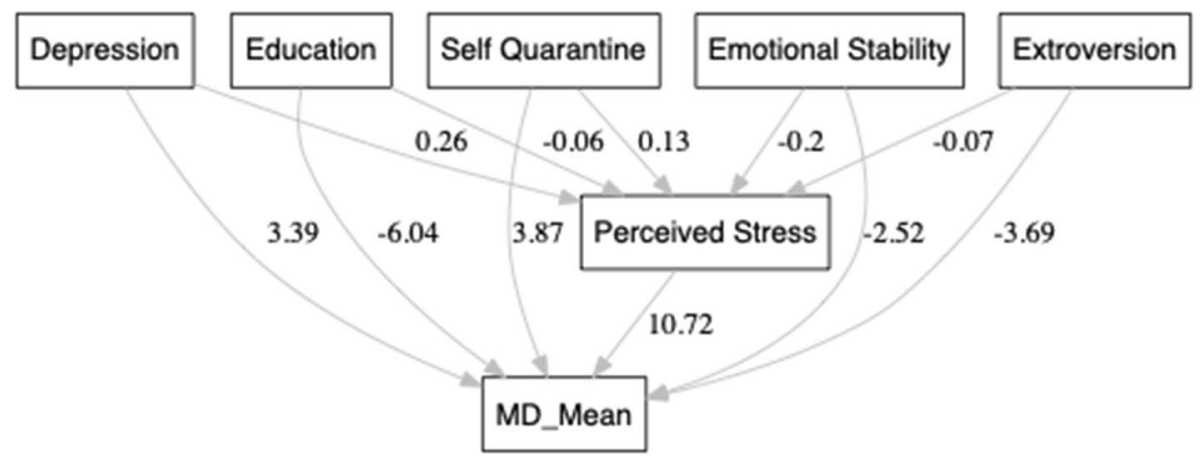

Fig. 2 Regression estimates of the employment of self-quarantine, lower level of education, introversion, and emotional instability

perceived stress mediated the associations between all measured independent variables and $\mathrm{MD}$, as shown in Table 3.

\section{Discussion}

As expected, self-quarantine and a past diagnosis of depression were associated with MD, confirming previous research showing that individuals with probable MD who were subject to lockdown restrictions and those with pre-existing mental health conditions reported had spent more time in intense fantasy (Somer et al., 2020). Many of our respondents who reported high MD levels spontaneously wrote to inform us how the home confinement disrupted their routines and generated boredom, loneliness, and sadness. The uncontrollability of the situation and stimulus deprivation motivated many to regulate their distress by resorting to their mental addiction for the relief of stress associated with the adversities.

Our data shed further light on personal characteristics associated with MD, suggesting that introversion and emotional instability are related to MD. Individuals with MD often experience difficulties managing problematic emotions and use their daydreaming as a fleeting escape (Bigelsen \& Schupak, 2011). Our results imply that the compensatory themes in MD fantasy might be particularly appealing to persons who are uncomfortable with real social interactions. Our data are in line with data showing that social anxiety is a risk factor for MD (Somer \& Herscu, 2017). Our findings are also in line with previously published data showing that MD is not an effective emotional regulation strategy (West \& Somer, 2020).

Table 3 Mediation model: indirect effects

\begin{tabular}{lllll}
\hline Indirect effect & Estimate & Std. error & $Z$ value & $P$ \\
\hline Past major depression & 2.77 & 0.62 & 4.45 & $<.001$ \\
Education & -0.62 & 0.27 & -2.26 & .02 \\
Self-quarantine & 1.38 & 0.44 & 3.11 & .002 \\
Extraversion & -0.72 & 0.14 & -5.09 & $<.001$ \\
Emotional stability & -2.13 & 0.25 & -8.53 & $<.001$ \\
\hline
\end{tabular}


We also found that during the lockdown, there was an inverse relationship between the level of education and MD severity. The association between education and mental health has been documented before (Niemeyer et al., 2019). It seems that individuals with low education had fewer psychological resources to cope with adversities and were, therefore, more likely to resort to ineffective forms of emotion regulation, such as MD.

Finally, we found that perceived stress was strongly related to MD. The pandemic and the lockdown stressors can be seen as a set of demands that individuals had perceived as exceeding their abilities and resources (Lazarus, 1991) and, thus, lead to negative outcomes, such as MD. Cognitive appraisals were previously shown to mediate the relationship between stress and psychological health (Gomes et al., 2016). Our findings indicate that perceived stress is an important underlying mechanism in explaining worsened MD in the shadow of the pandemic threat. Our data also imply that MD could be an unsuccessful attempt at stress regulation since self-quarantine seems to be associated with higher MD via an elevated subjective stress appraisal. In line with our previous report (Somer et al., 2020), the current data demonstrate that exacerbated MD can be a mental health consequence of the stressful effects of the lockdown. Several hypotheses concerning the general relationship between stress and MD have been suggested: Pietkiewicz et al. (2018) argued that MD is a type of behavioral addiction, initially developed as a mechanism for coping with stress. According to this hypothesis, immersion in vivid mental scenarios serves as a distraction from stressful circumstances and can relieve emotional tension. Although this hypothesis brings a plausible explanation to the association of stress and MD, from another point of view, a coping strategy may not be deemed as a behavioral addiction (KardefeltWinther et al., 2017). Based on these two views, we argue instead that immersive daydreaming (West \& Somer, 2020) might serve as an effective coping for some people but on the other end of the dimension, uncontrolled immersive daydreaming (MD) is associated with spending hours every day in fantasy which may be deemed addiction for others. It should also be noted that, according to Khantzian and Treece (1985), an addiction is facilitated when the addictive substance or behavior has self-medicating properties. So, MD might be first employed as self-medication to relieve uncomfortable sensations associated with stress, but it might later transform into a form of behavioral addiction that is independent of the stressful events.

In sum, individuals with lower education, previous depressive episodes, and specific traits such as introversion and emotional instability who experienced the pandemic and the ensuing social restrictions as stressful might require closer clinical monitoring. These results confirm our first research hypothesis and indicate that lockdown-related hardships may affect individuals with different personalities in different ways and degrees. This outcome might be important for tailoring the interventions during the current pandemic and other mass emergencies.

In line with our theoretical expectation and the second hypothesis, perceived stress emerged as an important mediator of the possible effects of psychological variables and self-quarantine on MD. The transactional model of stress (Folkman \& Lazarus, 1984) identifies two forms of cognitive appraisal that account for the experience of stress in response to an event: "primary appraisal" and "secondary appraisal". During the primary appraisal, an event is interpreted as a threat to the individual. During the secondary appraisal, the individual evaluates their ability or resources to be able to cope with a specific situation as inadequate. Our mediation model implies that under the objective circumstances of the pandemic, MD will worsen among at-risk individuals who tend to appraise the conditions as exceeding their ability to cope. 
At times of mass disasters and multi-casualty events, medical and mental health resources are prone to achieve insufficiency, often requiring the utilization of triage principles. Our data suggest that help efforts during mass casualty situations should focus on reaching out to the less educated and those with psychological vulnerabilities. However, our mediation model also shows that a promising intervention to moderate deteriorating psychiatric conditions such as MD is the instilling of cognitive reappraisal skills that can buffer the direct association between objective and personal risk factors and MD.

A couple of study caveats should be noted. First, our findings are based on a sizable international sample, and the sample was neither random nor representative; thus, generalizability is limited. Second, the mediator and all other variables were simultaneously assessed at a single time point in a cross-sectional design. A longitudinal research strategy could have allowed stronger conclusions regarding the role of perceived stress in our conceptual model. In conclusion, people prone to develop heightened MD symptoms during times of crisis may benefit from clinical interventions designed to improve behavior and emotion regulation, as these can help improve emotional stability and reduce perceived stress. Furthermore, providing skills to facilitate communication with others and to promote socialization via the available instruments (e.g., the Internet) might help these individuals, as more extraverted behaviors could protect them from an excessive escape into the fantasy world.

\section{Declarations}

Conflict of Interest The authors declare no competing interests.

\section{References}

Andersen, S. C., Gensowski, M., Ludeke, S. G., \& John, O. P. (2020). A stable relationship between personality and academic performance from childhood through adolescence. An original study and replication in hundred-thousand-person samples. Journal of Personality, 88(5), 925-939. https://doi.org/10. 1111/jopy. 12538

Balhara, Y., Kattula, D., Singh, S., Chukkali, S., \& Bhargava, R. (2020). Impact of lockdown following COVID-19 on the gaming behavior of college students. Indian Journal of Public Health, 64(Supplement), S172-S176. https://doi.org/10.4103/ijph.IJPH_465_20

Bergdahl, L., \& Bergdahl, M. (2002). Perceived stress in adults: Prevalence and association of depression, anxiety and medication in a Swedish population. Stress and Health, 18(5), 235-241. https://doi.org/10. 1002/smi.946

Bigelsen, J., \& Schupak, C. (2011). Compulsive fantasy: Proposed evidence of an under-reported syndrome through a systematic study of 90 self-identified non-normative fantasizers. Consciousness and Cognition: An International Journal, 20, 1634-1648. https://doi.org/10.1016/j.concog.2011.08.013

Bowling, A. (2005). Mode of questionnaire administration can have serious effects on data quality. Journal of Public Health (Oxford, England), 27(3), 281-291. https://doi.org/10.1093/pubmed/fdi031

Brooks, C., \& Moser, J. (2020). Surviving or thriving? Enduring COVID-19 as an introvert and extrovert. Available online at: https://msutoday.msu.edu/news/2020/surviving-or-thriving-enduring-covid-19asan-introvert-and-extrovert/. Accessed 20 Apr 2020.

Brooks, S. K., Webster, R. K., Smith, L. E., Woodland, L., Wessely, S., Greenberg, N., \& Rubin, G. J. (2020). The psychological impact of quarantine and how to reduce it: rapid review of the evidence. Lancet (London, England), 395(10227), 912-920. https://doi.org/10.1016/S0140-6736(20)30460-8

Centers for Disease Control and Prevention (2021). Covid-19 information page. https://www.cdc.gov/coron avirus/2019-ncov/index.html 
Chodkiewicz, J., Talarowska, M., Miniszewska, J., Nawrocka, N., \& Bilinski, P. (2020). Alcohol consumption reported during the COVID-19 pandemic: The initial stage. International Journal of Environmental Research and Public Health, 17(13), 4677. https://doi.org/10.3390/ijerph17134677

Cohen, S., Kamarck, T., \& Mermelstein, R. (1983). A global measure of perceived stress. Journal of Health and Social Behavior, 24, 385-396.

Elhai, J. D., Yang, H., MacKay, D., \& Asmundson, G. J. G. (2020). COVID-19 anxiety symptoms associated with problematic smartphone use severity in Chinese adults. Journal of Affective Disorders, 274, 576-582. https://doi.org/10.1016/j.jad.2020.05.080

Folkman, S., \& Lazarus, R. S. (1984). Stress, appraisal, and coping. Springer.

Gomes, A. R., Faria, S., \& Lopes, H. (2016). Stress and psychological health: Testing the mediating role of cognitive appraisal. Western Journal of Nursing Research, 38(11), 1448-1468. https://doi.org/ $10.1177 / 0193945916654666$

Gosling, S. D., Rentfrow, P. J., \& Swann, W. B. (2003). A very brief measure of the Big-Five personality domains. Journal of Research in Personality, 37(6), 504-528. https://doi.org/10.1016/s00926566(03)00046-1

Holingue, C., Kalb, L. G., Riehm, K. E., Bennett, D., Kapteyn, A., Veldhuis, C. B., Johnson, R. M., Fallin, M. D., Kreuter, F., Stuart, E. A., \& Thrul, J. (2020). Mental distress in the United States at the beginning of the COVID-19 pandemic. American Journal of Public Health, 110(11), 1628-1634. https://doi.org/10.2105/AJPH.2020.305857

Hu, L., \& Bentler, P. M. (1999). Cutoff criteria for fit indexes in covariance structure analysis: Conventional criteria versus new alternatives. Structural Equation Modeling: A Multidisciplinary Journal, 6(1), 1-55. https://doi.org/10.1080/10705519909540118

Kardefelt-Winther, D., Heeren, A., Schimmenti, A., Rooij, A. V., Maurage, P., Carras, M., ... Billieux, J. (2017). How can we conceptualize behavioural addiction without pathologizing common behaviours? Addiction, 112(10), 1709-1715. doi:https://doi.org/10.1111/add.13763

Kemper, C. J., Trapp, S., Kathmann, N., Samuel, D. B., \& Ziegler, M. (2019). Short versus long scales in clinical assessment: Exploring the trade-off between resources saved and psychometric quality lost using two measures of obsessive-compulsive symptoms. Assessment, 26(5), 767-782. https://doi. org/10.1177/1073191118810057

Khantzian, E. J. (1997). The self-medication hypothesis of substance use disorders: a reconsideration and recent applications. Harvard Review of Psychiatry, 4(5), 231-244. https://doi.org/10.3109/ 10673229709030550

Khantzian, E. J., \& Treece, C. (1985). DSM-III psychiatric diagnosis of narcotic addicts. Recent findings. Archives of General Psychiatry, 42(11), 1067-1071. https://doi.org/10.1001/archpsyc.1985. 01790340045007

Klinger, E. (2009). Daydreaming and fantasizing: Thought flow and motivation. In K. D. Markman, W. M. P. Klein, \& J. A. Suhr (Eds.), Handbook of imagination and mental simulation (pp. 225-239). Psychology Press.

Knack, J. M., Chen, Z., Williams, K. D., \& Jensen-Campbell, L. A. (2006). Opportunities and challenges for studying disaster survivors. Analyses of Social Issues and Public Policy, 6(1), 175-189. https:// doi.org/10.1111/j.1530-2415.2006.00116.x

Kowal, M., Sorokowski, P., Sorokowska, A., Dobrowolska, M., Pisanski, K., Oleszkiewicz, A., ... Zupančič, M. (2020). Reasons for Facebook usage: Data from 46 countries. Frontiers in Psychology, 11. doi:https://doi.org/10.3389/fpsyg.2020.00711.

Lazarus, R. S. (1991). Emotion and adaptation. Oxford University Press.

Li, Q. (2020). Psychosocial and coping responses toward 2019 coronavirus diseases (COVID-19): a cross-sectional study within the Chinese general population. QJM: Monthly Journal of the Association of Physicians, 113(10), 731-738. https://doi.org/10.1093/qjmed/hcaa226

Liu, C. H., Zhang, E., Wong, G., Hyun, S., \& Hahm, H. C. (2020). Factors associated with depression, anxiety, and PTSD symptomatology during the COVID-19 pandemic: Clinical implications for U.S. young adult mental health. Psychiatry Research, 290, 113172. https://doi.org/10.1016/j.psychres. 2020.113172

Liu, S., Lithopoulos, A., Zhang, C. Q., Garcia-Barrera, M. A., \& Rhodes, R. E. (2021). Personality and perceived stress during COVID-19 pandemic: Testing the mediating role of perceived threat and efficacy. Personality and Individual Differences, 168, 110351. https://doi.org/10.1016/j.paid.2020. 110351

Megatsari, H., Laksono, A. D., Ibad, M., Herwanto, Y. T., Sarweni, K. P., Geno, R., \& Nugraheni, E. (2020). The community psychosocial burden during the COVID-19 pandemic in Indonesia. Heliyon, 6(10), e05136. https://doi.org/10.1016/j.heliyon.2020.e05136 
Mental health Research, Canada. (2020). Mental health during COVID-19 outbreak. Findings of poll 1. https://www.mhrc.ca/national-poll-covid/findings-of-poll-1

Mooneyham, B. W., \& Schooler, J. W. (2013). The costs and benefits of mind-wandering: A review. Canadian Journal of Experimental Psychology/Revue canadienne de psychologie experimentale, 67(1), 11-18. https://doi.org/10.1037/a0031569

Murray, C. J., Vos, T., Lozano, R., Naghavi, M., Flaxman, A. D., Michaud, C., ... Memish, Z. A. (2012). Disability-adjusted life years (DALYs) for 291 diseases and injuries in 21 regions, 1990-2010: A systematic analysis for the Global Burden of Disease Study 2010. Lancet, 380(9859), 2197-2223. https://doi.org/10.1016/S0140-6736(12)61689-4

Musetti, A., Franceschini, C., Pingani, L., Freda, M. F., Saita, E., Vegni, E., Zenesini, C., Quattropani, M. C., Lenzo, V., Margherita, G., Lemmo, D., Corsano, P., Borghi, L., Cattivelli, R., Plazzi, G., Castelnuovo, G., Somer, E., \& Schimmenti, A. (2021). Maladaptive daydreaming in an adult Italian population during the COVID-19 lockdown. Frontiers in Psychology, 12, 631979. https://doi.org/ 10.3389/fpsyg.2021.631979

Niemeyer, H., Bieda, A., Michalak, J., Schneider, S., \& Margraf, J. (2019). Education and mental health: Do psychosocial resources matter? SSM - Population Health, 7, 100392. https://doi.org/10.1016/j. ssmph.2019.100392

OECD. (2012). How does education affect employment rates? In education at a glance 2012: Highlights. Paris: OECD Publishing. https://doi.org/10.1787/eag_highlights-2012-11-en

Pietkiewicz, I. J., Nęcki, S., Bańbura, A., \& Tomalski, R. (2018). Maladaptive daydreaming as a new form of behavioral addiction. Journal of Behavioral Addictions, 7(3), 838-843. https://doi.org/10. 1556/2006.7.2018.95

Preti, E., Di Mattei, V., Perego, G., Ferrari, F., Mazzetti, M., Taranto, P., Di Pierro, R., Madeddu, F., \& Calati, R. (2020). The psychological impact of epidemic and pandemic outbreaks on healthcare workers: Rapid review of the evidence. Current Psychiatry Reports, 22(8), 43. https://doi.org/10. $1007 / \mathrm{s} 11920-020-01166-\mathrm{z}$

Price, A. (2020). Online gambling in the midst of COVID-19: A nexus of mental health concerns, substance use and financial stress. International Journal of Mental Health and Addiction, 1-18. https:// doi.org/10.1007/s11469-020-00366-1

Rogers, A. H., Shepherd, J. M., Garey, L., \& Zvolensky, M. J. (2020). Psychological factors associated with substance use initiation during the COVID-19 pandemic. Psychiatry Research, 293, 113407. https://doi.org/10.1016/j.psychres.2020.113407

Rubin, G. J., \& Wessely, S. (2020). The psychological effects of quarantining a city. BMJ (Clinical research ed.), 368, m313. https://doi.org/10.1136/bmj.m313

Schimmenti, A., Somer, E., \& Regis, M. (2019). Maladaptive daydreaming: Towards a nosological definition. Annales Médico-Psychologiques, 177(9), 865-874. https://doi.org/10.1016/j.amp.2019.08. 014

Schimmenti, A., Billieux, J., \& Starcevic, V. (2020a). The four horsemen of fear: An integrated model of understanding fear experiences during the COVID-19 pandemic. Clinical Neuropsychiatry, 17(2), 41-45.

Schimmenti, A., Sideli, L., La Marca, L., Gori, A., \& Terrone, G. (2020b). Reliability, validity, and factor structure of the Maladaptive Daydreaming Scale (MDS-16) in an Italian sample. Journal of Personality Assessment, 102(5), 689-701.

Sim, K. (2010). Psychosocial and coping responses within the community health care setting towards a national outbreak of an infectious disease. Journal of Psychosomatic Research, 68, 195-202.

Sohrabi, C., Alsafi, Z., O’Neill, N., Khan, M., Kerwan, A., Al-Jabir, A., Iosifidis, C., \& Agha, R. (2020). World Health Organization declares global emergency: A review of the 2019 novel coronavirus (COVID-19). International journal of surgery (London, England), 76, 71-76. https://doi.org/10. 1016/j.ijsu.2020.02.034

Somer, E. (2002). Maladaptive daydreaming: A qualitative inquiry. Journal of Contemporary Psychotherapy, 32(2), 195-210.

Somer, E. (2018). Maladaptive daydreaming: Ontological analysis, treatment rationale and a pilot case report. Frontiers in the Psychotherapy of Trauma and Dissociation, 1(2), 1-22.

Somer, E., \& Herscu, O. (2017). Childhood trauma, social anxiety, absorption and fantasy dependence: Two potential mediated pathways to maladaptive daydreaming. Journal of Addictive Behaviors, Therapy \& Rehabilitation., 06, . https://doi.org/10.4172/2324-9005.1000170

Somer, E., Lehrfeld, J., Bigelsen, J., \& Jopp, D. S. (2016). Development and validation of the maladaptive daydreaming scale (MDS). Consciousness and Cognition, 39, 77-91. https://doi.org/10.1016/j. concog.2015.12.001 
Somer, E., Abu-Rayya, H. M., Schimmenti, A., Metin, B., Brenner, R., Ferrante, E., Göçmen, B., \& Marino, A. (2020). Heightened levels of maladaptive daydreaming are associated with COVID-19 lockdown, pre-existing psychiatric diagnoses, and intensified psychological dysfunctions: A multicountry study. Frontiers in Psychiatry, 11, 587455. https://doi.org/10.3389/fpsyt.2020.587455

Soto, C. J., \& John, O. P. (2017). The next Big Five Inventory (BFI-2): Developing and assessing a hierarchical model with 15 facets to enhance bandwidth, fidelity, and predictive power. Journal of Personality and Social Psychology, 113, 117. https://doi.org/10.1037/pspp0000096

Steel, P., Schmidt, J., \& Shultz, J. (2008). Refining the relationship between personality and subjective well-being. Psychological Bulletin, 134, 138. https://doi.org/10.1037/0033-2909.134.1.138

Thorsen, F., Antonson, C., Sundquist, J., \& Sunfquist, K. (2016). Perceived stress and psychiatric symptoms in Swedish upper secondary school students. Journal of Educational and Developmental Psychology, 6(2), 183-194. https://doi.org/10.5539/jedp.v6n2p183

Van Bortel, T. (2016). Psychosocial effects of an Ebola outbreak at individual, community and international levels. Bulletin of the World Health Organization, 94, 210-214.

Wang, C., Pan, R., Wan, X., Tan, Y., Xu, L., Ho, C. S., et al. (2020). Immediate psychological responses and associated factors during the initial stage of the 2019 coronavirus disease (COVID-19) epidemic among the general population in China. International Journal of Environmental Research and Public Health, 17, 17-29.

Wathelet, M., Duhem, S., Vaiva, G., Baubet, T., Habran, E., Veerapa, E., Debien, C., Molenda, S., Horn, M., Grandgenèvre, P., Notredame, C. E., \& D’Hondt, F. (2020). Factors associated with mental health disorders among university students in France confined during the COVID-19 pandemic. JAMA Network Open, 3(10), e2025591. https://doi.org/10.1001/jamanetworkopen.2020.25591

West, M., \& Somer, E. (2020). Empathy, emotion regulation and creativity in immersive daydreaming. Imagination, Cognition and Personality, 39(4), 358-373. https://doi.org/10.1177/0276236619864277

Wijngaards, I., Sisow de Zilwa, S. C. M., \& Burger, M. (2020). Extraversion moderates the relationship between the stringency of COVID-19 protective measures and depressive symptoms. Frontiers in Psychology, 11, 568907. https://doi.org/10.3389/fpsyg.2020.568907

Wiklund, M., Malmgren-Olsson, E. B., Öhman, A., et al. (2012). Subjective health complaints in older adolescents are related to perceived stress, anxiety and gender - A cross-sectional school study in Northern Sweden. BMC Public Health, 12, 993. https://doi.org/10.1186/1471-2458-12-993

Woodcock, A., Graziano, W. G., Branch, S. E., Habashi, M. M., Ngambeki, I., \& Evangelou, D. (2013). Person and thing orientations: Psychological correlates and predictive utility. Social Psychological and Personality Science, 4, 116-123. https://doi.org/10.1177/1948550612444320

Xu, C., Xu, Y., Xu, S., Zhang, Q., Liu, X., Shao, Y., Xu, X., Peng, L., \& Li, M. (2020). Cognitive reappraisal and the association between perceived stress and anxiety symptoms in COVID-19 isolated people. Frontiers in Psychiatry, 11, 858. https://doi.org/10.3389/fpsyt.2020.00858

Zandifar, A., Badrfam, R., Yazdani, S., et al. (2020). Prevalence and severity of depression, anxiety, stress and perceived stress in hospitalized patients with COVID-19. Journal of Diabetes and Metabolic Disorders, 19, 1431-1438. https://doi.org/10.1007/s40200-020-00667-1

Publisher's Note Springer Nature remains neutral with regard to jurisdictional claims in published maps and institutional affiliations. 